Discussion

Papers

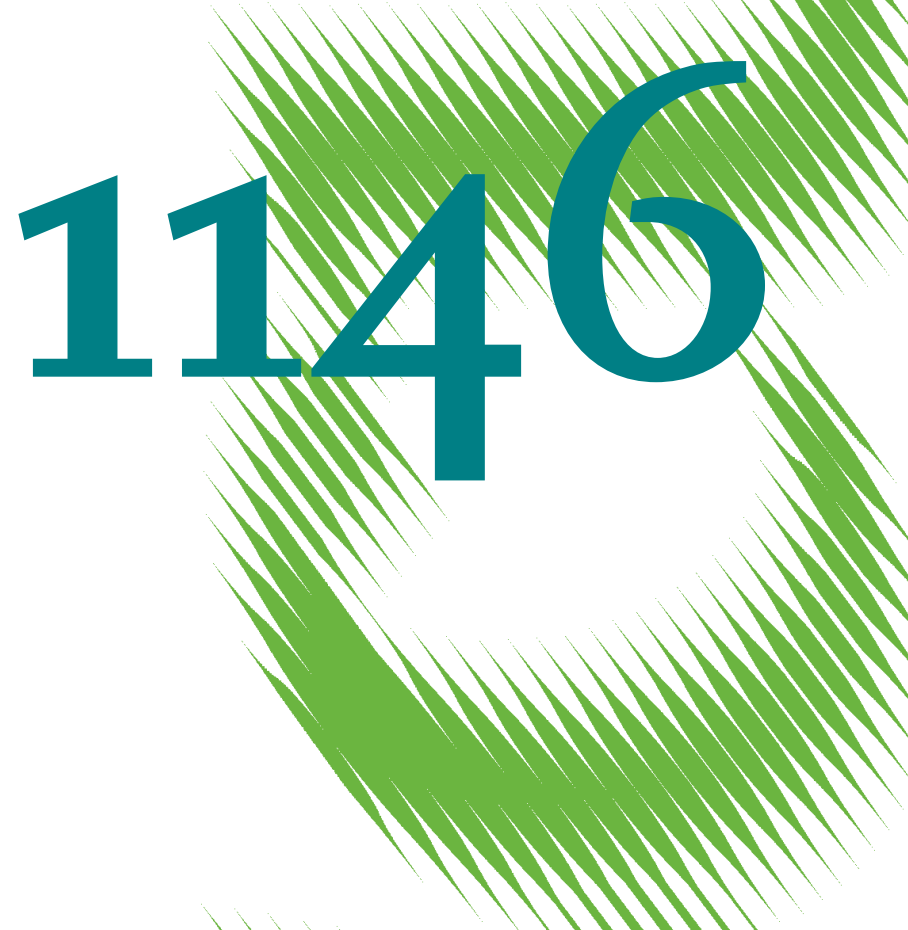

What about Coal? Interactions between Climate Policies and the Global Steam Coal Market until 2030 
Opinions expressed in this paper are those of the author(s) and do not necessarily reflect views of the institute.

IMPRESSUM

(C) DIW Berlin, 2011

DIW Berlin

German Institute for Economic Research

Mohrenstr. 58

10117 Berlin

Tel. $+49(30) 89789-0$

Fax +49 (30) $89789-200$

http://www.diw.de

ISSN print edition $1433-0210$

ISSN electronic edition 1619-4535

Papers can be downloaded free of charge from the DIW Berlin website:

http://www.diw.de/discussionpapers

Discussion Papers of DIW Berlin are indexed in RePEc and SSRN:

http://ideas.repec.org/s/diw/diwwpp.html

http://www.ssrn.com/link/DIW-Berlin-German-Inst-Econ-Res.html 


\title{
What about coal? Interactions between climate policies and the global steam coal market until $2030^{*}$
}

\author{
Clemens Haftendorn, Claudia Kemfert, and Franziska Holz \\ German Institute for Economic Research (DIW Berlin) \\ Mohrenstr. 58, 10117 Berlin, Germany \\ Tel. +49-30-89789-206, Fax +49-30-89789-113 \\ \{chaftendorn/ckemfert/fholz\}@diw.de
}

August 3, 2011

${ }^{*}$ We would like to thank Marco Springmann for his expertise on CGE models, Steven A. Gabriel, Ruud Egging, Andreas Schröder and Jan Abrell for their helpful comments and suggestions as well as Tim Winke for research assistance. All remaining errors are ours. 


\begin{abstract}
Because of economic growth and a strong increase in global energy demand the demand for fossil fuels and therefore also greenhouse gas emissions are increasing, although climate policy should lead to the opposite effect. The coal market is of special relevance as coal is available in many countries and often their first choice to meet energy demand. In this paper we assess possible interactions between climate policies and the global steam coal market. Possible market adjustments between demand centers through market effects are investigated with a numerical model of the global steam coal market until 2030: the "COALMOD-World" model. The COALMOD-World model is an equilibrium model that computes future trade flows, infrastructure investments and prices until 2030. We investigate three specific designs of climate policy: a unilateral European climate policy, an Indonesian export-limiting policy and a carbon capture and storage (CCS) fast-roll out policy in the broader context of climate policy and market constraints. We find that market adjustment effects in the coal market can have significant positive and negative impacts on the effectiveness of climate policies.
\end{abstract}

Keywords: climate policy, future coal production, energy, numerical modeling, international trade. 


\section{Introduction}

This paper presents an analysis of the different possible interactions between climate policies and the global steam coal market. Worldwide steam coal consumption is continuously growing, drawn by economic growth and increasing electricity demand in Asia. The use of coal is also a major contributor to global carbon dioxide emissions that have a potentially high adverse effect on the future climate. Hence, the relationship between the coal market and climate policy is of prime importance for the effectiveness of these policies and needs to be investigated further.

In the set of possible interactions we show that a shift of production towards the present due to strategic behavior of coal resource owners as a reaction to future climate policies is not to be expected. We therefore concentrate our analysis on pure supply and demand market effects using the COALMOD-World model described in Haftendorn et al. (2010). This multi-period model of the global steam coal market calculates yearly future market equilibria. We implement three different climate policy shocks in different climate policy and market environments already in place. The scenarios are: a unilateral European climate policy, an Indonesian export-limiting supply-side policy and a carbon capture and storage (CCS) fast roll-out policy.

Our main findings are that coal market adjustments effects can have a potentially adverse effect on climate policy effectiveness in the case of an unilateral European climate policy. However this effect never overcompensates saved emissions; even a unilateral European climate effort will always be beneficial to the global climate. In the case of the Indonesian supply-side scenario and the CCS fast-roll out policy we see positive market adjustment effects that speak for the effectiveness of these less conventional measures. After having evaluated the different modeling results, we draw conclusions and policy recommendations for the climate policy of the European Union (EU).

\section{Assessment of positive modeling approaches}

\subsection{Overview of possible modeling approaches}

There are various modeling approaches at our disposition to help us understand what possible effects we can expect from the interaction between climate policies and the global steam coal market. In essence, all these models are positive, meaning that they are "constructed with the objective of better explaining (or reproducing) observed resource prices and production levels"(Pindyck, 1981). The classical model for the theory of exhaustible resource extraction was developed by Hotelling (1931) 
and has recently been used for the assessment of climate policies (see Sinn, 2008). In the following section 2.2 we determine if these models can be applied to the global steam coal market.

Another type of modeling approach for resource markets is based on the concept of the Hubbert curve first described by M. King Hubbert (1959). The core mathematical assumption of this model is that cumulative resource production follows a logistic growth path that derived with respect to time yields the well-known symmetrical bell shaped curve of yearly production output; the summit of the curve representing the "peak" of the production rate. It is mathematically possible to estimate the shape of the curve and, thus, the peak year as well as the ultimately recoverable reserves, defined as the surface under the curve, based solely on historical production data. This simple technique is subject to controversy. Its proponents claim that "the Hubbert curves are based on [...] production and not on ill-defined and subjective [...] 'reserves'" and that "historical production trends reflect the prevailing economics prior to the time of production" (Patzek and Croft, 2010). However its opponents, such as Lynch (2003), state that the "work of the Hubbert modelers has proven to be incorrect in theory, and based heavily on assumptions that the available evidence shows to be wrong. They have repeatedly misinterpreted political and economic effects as reflecting geological constraints, and misunderstood the causality underlying exploration, discovery and production". The main problem for our analysis of climate policy is that past production can only represent past economical and political situations. The Hubbert model fails to integrate paradigm shifts that will affect future production patterns such as the carbon constraints of climate policy or the high economic growth in Asia. It is thus not suitable for our purpose.

Computable General Equilibrium models (CGE) have been widely used for climate policy analyses. For example, Böhringer and Rutherford (2000) analyze the economic implications of the Kyoto Protocol at the cross-country level, while Böhringer et al. (2010) assess the effects of regional climate policies on industrial sectors' competitiveness and the scope for carbon leakage, i.e., the increase in carbon emissions outside emissions-regulating regions, e.g., due to relocation. Bovenberg and Goulder (2005) place greater focus on industries affected by carbon-emissions regulation. Kemfert (2002) assesses potential leakage effects and compensation options by issue linkage. However, detailed industry, sector or market-level investigations require modifications to traditional CGE models which generally exhibit only coarse representations of the energy sector. One possible modification is to integrate topdown CGE models with bottom-up engineering models (e.g. Böhringer, 1998); another one is to utilize detailed partial equilibrium models that focus specifically on 
a single market or sector (e.g. Demailly and Quirion, 2008). However, since the focus and advantage of CGE models is the multi-sectoral analysis and carbon leakage through relocation effects, they would not be the best fit for the aim of our present study that focuses solely on interactions between climate policy and the steam coal market.

More recently resource markets have been investigated using partial equilibrium modeling techniques with a main focus on market power issues (e.g. Holz et al., 2008). We show in section 2.3 that partial equilibrium model are also suitable for climate policy analysis.

\subsection{Applicability of standard resource economics models}

The classical Hotelling (1931) model is built on the assumption of a known finite stock of a resource that will be depleted over time. The resource owner chooses the optimal extraction path over time in order to maximize his profit ${ }^{1}$ :

$$
\max \int_{0}^{T} \Pi_{t} e^{-i t} d t
$$

subject to the resource constraint for the cumulative extraction:

$$
\int_{0}^{T} R_{t} d t=\bar{S}
$$

The first order conditions imply that the net price, or scarcity rent grows exponentially with the interest rate as stated by Hotelling's efficiency rule: $P_{t}=P_{0} e^{i t}$.

There has been a recent stream of literature using Hotelling type resource economics models to assess the reaction of resource markets and resource owners to climate policies. The first and most prominent paper by Hans-Werner Sinn (2008) also coined the term "green paradox" to describe the potential adverse effect climate policies may have on total carbon emissions due to the reactions of resource owners. The underlying mechanisms are highlighted in Figure 1 for a finite carbon-based resource. The continuous lines in both graphs representing the price, the net price and the extraction path show the results of the classic Hotelling model described above. We use variable non-zero marginal costs to obtain a more realistic extraction path and a U-shaped price path. According to Sinn (2008), if a demand reducing climate policy is implemented with increasing intensity in the future, the resource owners will change the extraction path such that more of the resource is extracted today. This is represented by the dotted extraction line in Figure 1. This reaction is only possible by lowering the price to consumers $P C_{t}$ resulting in a lower net price

\footnotetext{
${ }^{1}$ We use the same notation and formulation as Perman et al. (1999).
} 


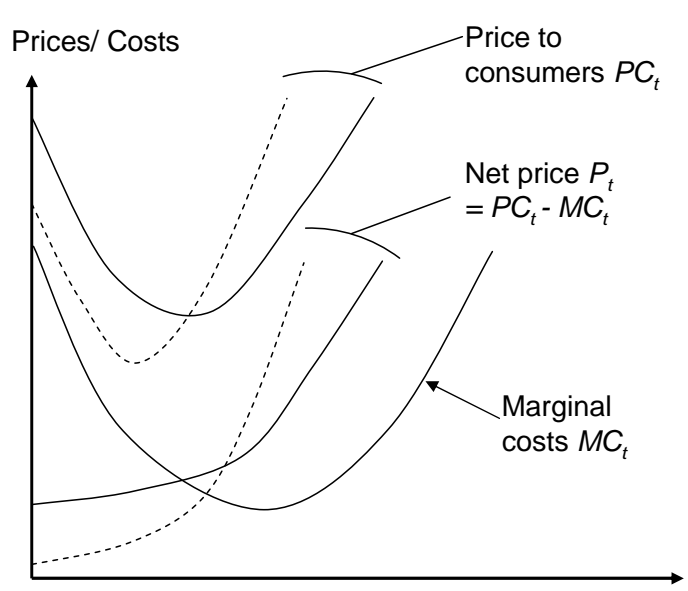

Time $t$

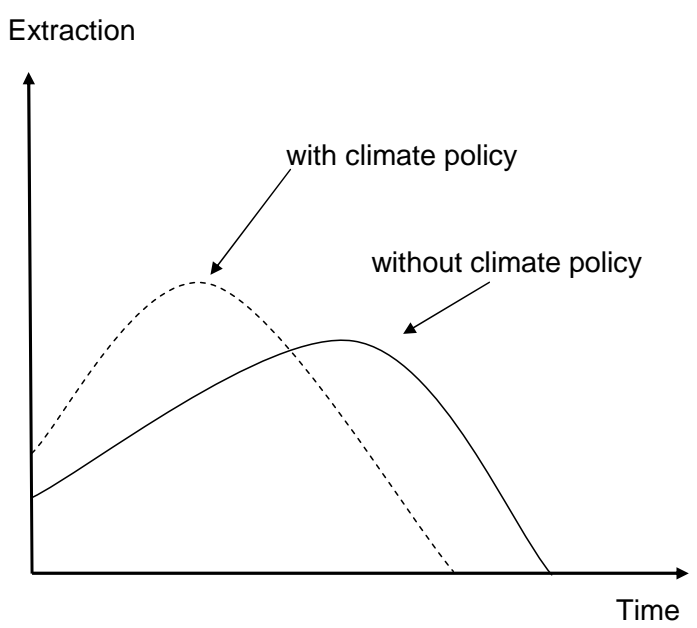

Figure 1: The effect of demand reducing climate policy in an Hotelling framework (source: own)

$P_{t}$ in earlier years. The profit of the resource owners is reduced but they still manage to sell all of their resource. Sinn (2008) concludes that "demand reducing measures of the type emphasized by politicians and in the public debate may be useless or even dangerous".

For this theory to apply in resource markets, there is one fundamental condition: the net price $P_{t}$ or scarcity rent must be strictly positive. In solving a Hotelling model this is ensured by the optimality conditions (see Perman et al., 1999, p. 175) with a terminal point in time where the resource stock and the extraction are zero. But if "the terminal value of the state variables is free, the transversality condition will always require that the shadow price of the state variable is zero"(Perman et al., 1999, p. 176). This is the case when the resource stock is very high. Indeed, in the case of coal, as we can see in Figure 2, the IPCC (2011) estimates that only about $30 \%$ of the coal in the ground will be used by 2100 . We can also assume that the entire stock will never be depleted due to climate policies already in place. With this information it is hard to see how a positive scarcity rent $P_{t}$ could arise in the time frame relevant to climate policy, if it ever arises. Without a positive scarcity rent and assuming a competitive coal market (see Haftendorn and Holz, 2010) the "green paradox" effect cannot occur on the steam coal market: prices equal the marginal costs of the marginal supplier and supply follows demand. For the near and middleterm climate policy effectiveness other effects are more relevant as we show in the next section. 


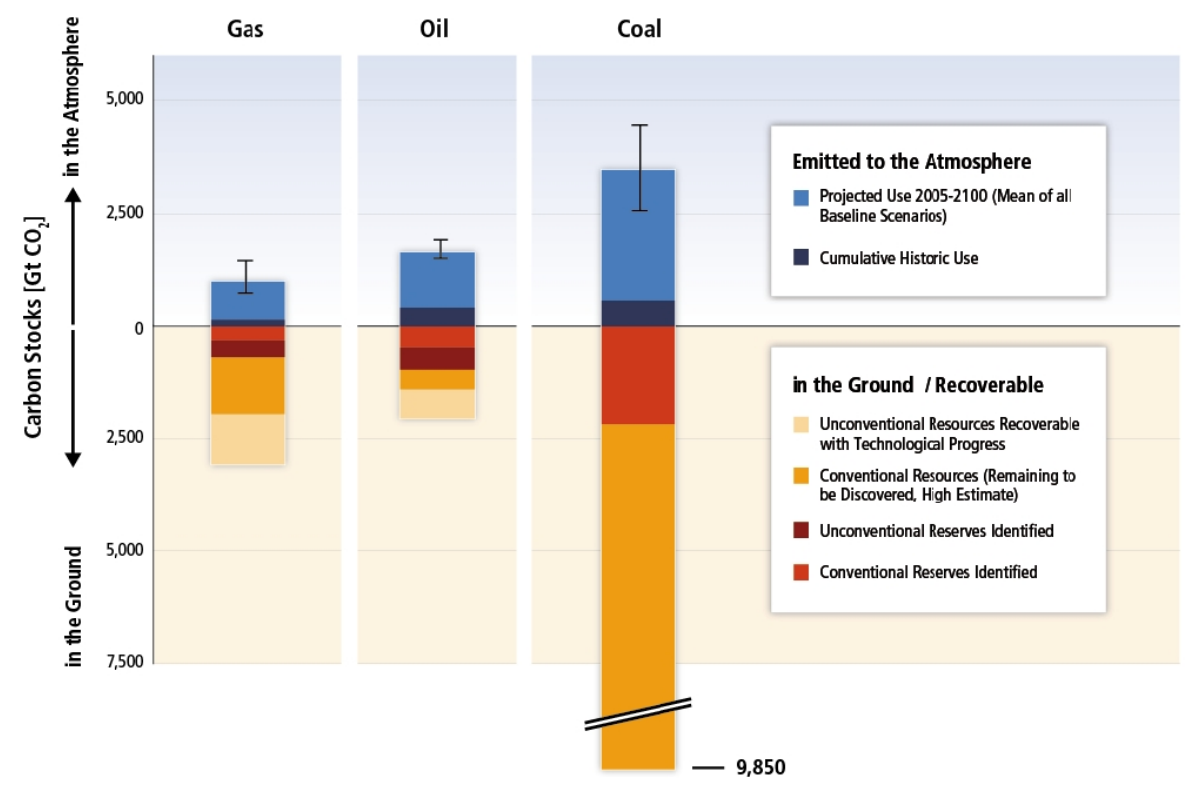

Figure 2: Projected carbon emissions from fossil fuels and amounts in the ground (source: IPCC, 2011)

\subsection{Advantages of partial equilibrium models and the COAL- MOD-World model}

Having ruled out the possibility of a large-scale reaction of coal resource owners to demand reducing climate policies in Section 2.2, and since we want to focus on the interaction of the coal market with climate policies only (and not with carbon leakage in general that would require CGE model as described in Section 2.1), we now concentrate on the remaining market effects. The introduction of heterogeneous types of climate policies, geographically as well as in the policy type, will affect the market supply and demand balance both locally and globally. The future use of coal in the world will be primarily influenced by climate policies, which will consequently affect the quantities of steam coal demanded. Quantity effects on the supply or demand side have price effects on the global market of steam coal and in turn, as there is an elastic demand for coal, influence coal consumption. These "market adjustments" can affect the effectiveness of climate policy in a positive or negative way. Partial equilibrium models are the ideal way to assess these effects since detailed market effects are at the core of these models.

Comparative static or multi-period scenario analyses have been widely used with partial equilibrium models, especially in the natural gas sector. Surprisingly, they

\footnotetext{
${ }^{2}$ This mechanism has also been described as being part of the carbon leakage mechanisms in the literature (see Dröge, 2009) but is rarely analyzed. To avoid confusion we restrict the term leakage only to industrial operations' relocation and investment effects and introduce the term "market adjustments" for pure market effects.
} 
have not been used much for climate policy scenarios yet. One main focus has been on market power (e.g. Lise and Hobbs, 2008, Holz et al., 2008) and other scenarios include demand scenarios, supply modifications, investment constraints and disruptions (e.g. Lise et al., 2008, Huppmann et al., 2011). The numerical modeling literature for the coal market has focused on market power issues (Haftendorn and Holz, 2010; Paulus and Trüby, 2011b) or infrastructure decisions (Paulus and Trüby, 2011a).

The COALMOD-World model, described in Haftendorn et al., 2010, is a multiperiod partial equilibrium model of the global steam coal market. It calculates yearly market equilibria for traded prices and quantities for the years 2006, 2010, 2015, 2020, 2025 and 2030 as well as investments in production and transport capacities between those years. The profit maximizing players are 25 producers and 14 exporters serving a total of 41 demand centers. The market is assumed to be competitive following the results in Haftendorn and Holz (2010). Virtually all worldwide steam coal demand is included as we model both domestic markets and the global seaborne market. The level of detail and disaggregation of the COALMOD-World model allows for a differentiated analysis of potential market adjustment effects as a reaction to climate policies.

\section{Climate policy scenarios with the COALMOD- World model}

A partial equilibrium model such as the COALMOD-World model allows for a broad range of possible scenario. Out of this set we have to choose the most relevant scenarios and ensure scenario consistency.

As stated before, climate policy is expected to be the main driver of steam coal demand in the future. Thus, we divide the scenario space in three possible futures of global climate policy intensity as defined by the IEA (2010) World Energy Outlook (WEO). These scenarios are ordered here from the less intense climate policy implementation to the most: the Current Policies scenario, the New Policies scenario and the $450 \mathrm{ppm}$ scenario. In the IEA Current Policies scenario, it is assumed that as of mid-2010 no change in the current policies will be implemented and that the recently announced commitments are not acted upon. In the New Policies scenario, the recently announced commitments and policies, for example from the 2009 Copenhagen Climate Conference, are fully implemented. Finally the $450 \mathrm{ppm}$ scenario is named after the low carbon dioxide concentration in the atmosphere that is reached in order to keep the increase in global average temperatures below $2^{\circ} \mathrm{C}$. 


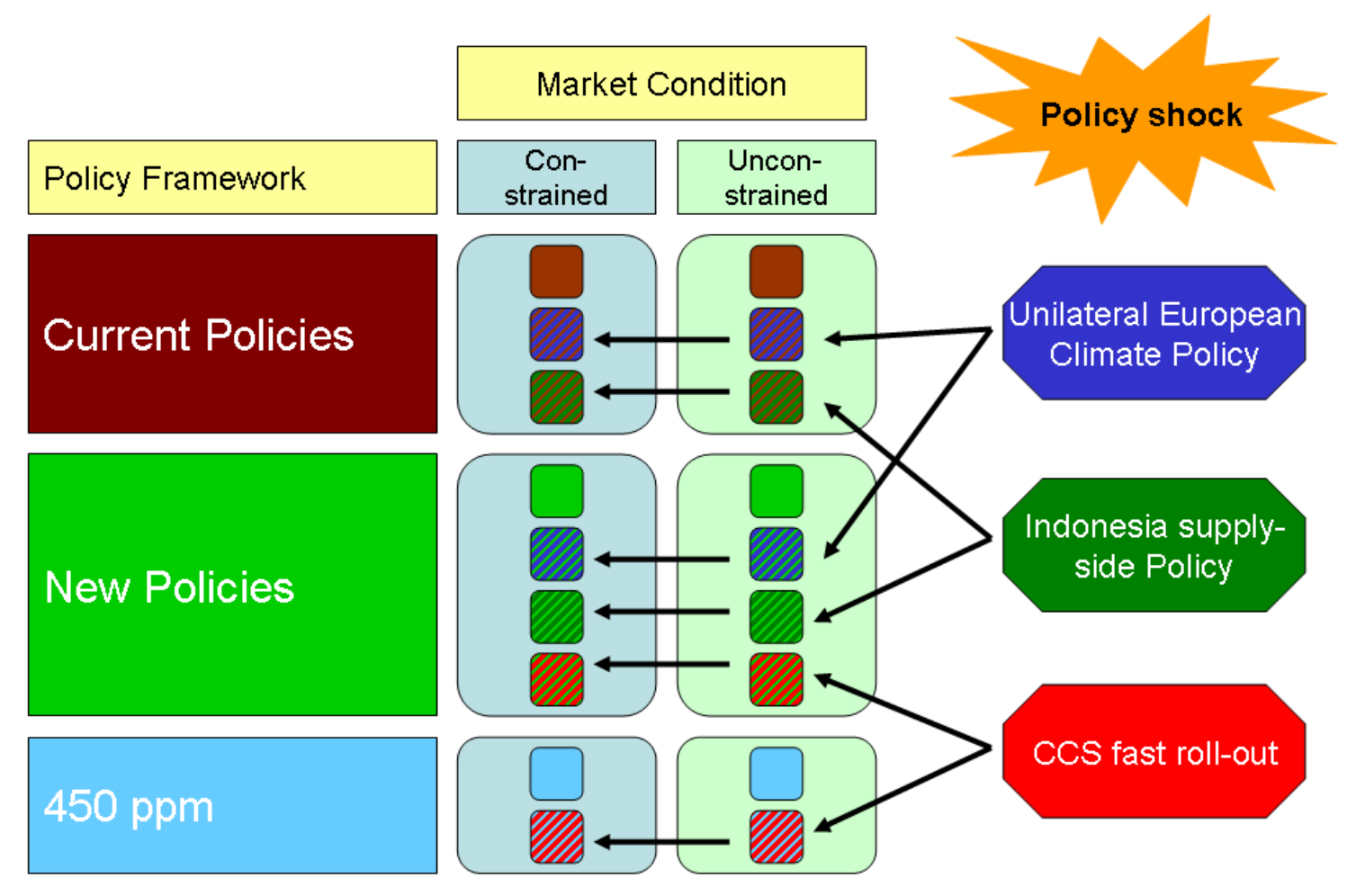

Figure 3: Scenario space

The second division of the scenario space is made by an exogenous market constraint. We assume that there are restrictions on production capacity expansions for various reasons that can be geological, technical and economical (financial restrictions, lack of qualified labor force or equipment). For the constrained case, the level of these restriction is based on historical capacity data provided by the USGS in the country reports of the Mineral Yearbook ${ }^{3}$ and on historical production data. This is a rather conservative assessment that can be regarded as the upper bound on the axis of the possible levels of exogenous market constraints. At the other extreme, these restrictions are completely lifted in the unconstrained case and the model producers can thus invest in production capacity as much as needed to maximize their profits.

Figure 3 shows all the scenarios implemented for this paper as the little squares in their respective scenario space (policy framework and market condition) and, where it applies, with the additional policy shock implemented. We investigate the effects of three policy shocks in this paper: a unilateral climate policy by Europe, a restriction of Indonesian coal production and exports, and a fast roll-out of CCS. They are described in the following Sections 3.2 to 3.4. To ensure scenario consistency and comparability the shocks are applied to the six reference scenarios (plain-colored

\footnotetext{
${ }^{3}$ http://minerals.usgs.gov/minerals/pubs/country/
} 
squares) and the results of the policy shock simulations are compared to their respective reference case. The reference cases are calibrated such that for most of the demand centers the consumed steam coal quantities are in a 10\% range above or below the quantities defined by the IEA (2010) WEO. As our demand functions are constructed using a reference demand, a reference price and a demand elasticity, we calibrate the references prices to fit the quantities. We calibrate such that at least $80 \%$ of the demand nodes for all model years are in the $10 \%$ range above and below the WEO quantities of their respective scenario.

A difficult issue in partial equilibrium analysis are price elasticities of demand due to the lack of econometric studies. Paulus and Trüby (2011b) give an overview of the results of econometric studies that estimate short-term price elasticities for coal. The range is between -0.05 and -0.57 . The elasticities for the base year 2006 are based on our previous work (Haftendorn et al., 2010). The elasticities of the following years are gradually set higher as we assume that countries will have a more diverse energy mix and higher flexibility in their power systems in the future.

\subsection{Worldwide climate policy}

Before we describe the outcomes of the scenarios resulting from an additional policy shock on an already implemented level of global climate policy, we analyze the model outcomes from these global climate policies that represent our reference cases. We have three different levels of global climate policy: the Current Policies scenario, the New Policies scenario and the $450 \mathrm{ppm}$ scenario based on the projections of the IEA (2010) WEO. Additionally to that policy framework we have to consider the market conditions as shown in Figure 3. In one case, investments in production capacity are constrained, in the other case they are not in order to represent two extremes of a continuum of exogenous market constraints.

Figure 4 shows the results from the different modeling runs of the reference cases in million tons of carbon dioxide emissions. Since the emissions are proportionally linked to the consumption of coal in energy units we can also infer the development of consumption and trade from these figures. The blue area represents the emissions in the $450 \mathrm{ppm}$ scenario (the same as for the other scenarios in 2010), adding the green area represents the emissions from the New Policies scenario and all the areas together show the emissions in the Current Policies scenario.

In the case of unconstrained investment possibilities in production capacity, coal consumption is significantly higher in the Current Policies scenario and slightly higher in the New Policies scenario. Global seaborne trade remains important and will continue to grow. We see a reduction in global trade only in the $450 \mathrm{ppm}$ 


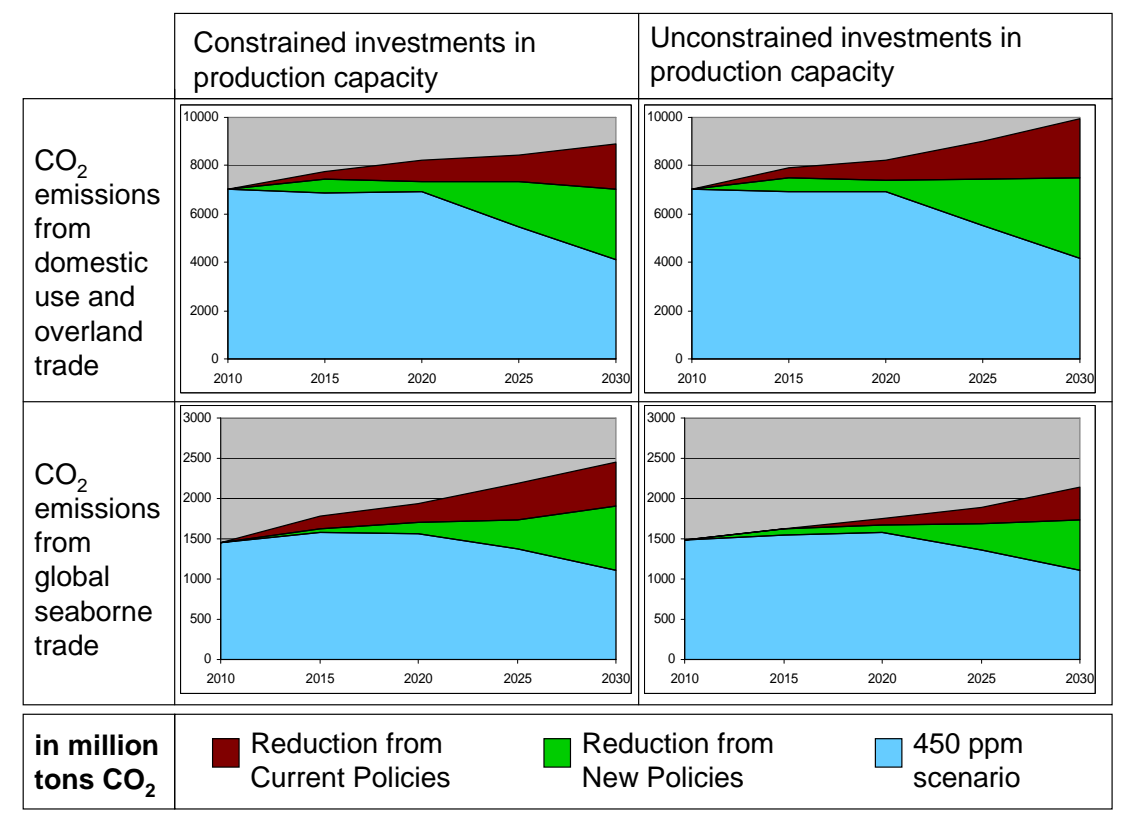

Figure 4: Annual carbon dioxide emissions from steam coal consumption in the six reference scenarios (source: own modeling results)

scenario. In the case of a constrained market condition global seaborne trade is especially important to help countries like China and India to meet their coal demand as they might experience in difficulties in expanding their domestic production base.

\subsection{Unilateral European climate policy}

The unilateral European climate policy scenario is implemented in two global climate policy frameworks: the Current Policies and the New Policies framework as shown in the scenario overview of Figure 3. In this scenario the European Union goes a step further and aims at reducing $\mathrm{CO}_{2}$ emissions by $30 \%$ compared to the level of 1990 by 2020 with further reductions in the future. This goal is reached through a significantly lower coal consumption in the European Union. In the IEA (2010) WEO scenarios this is represented by the demand values of the $450 \mathrm{ppm}$ scenario. The steam coal demand reduction compared to the reference scenarios are shown in Table 1.

The modeling results are shown in Figure 5. The blue area are represents the actual emissions reduction in the EU due to the EU unilateral climate policy. The grey area are the targeted emissions and together with the orange market adjustments they represent the actual global emissions. We can see that, given certain conditions, market adjustments can seriously undermine a unilateral European cli- 


\begin{tabular}{|l|l|l|l|}
\hline & $\mathbf{2 0 2 0}$ & $\mathbf{2 0 2 5}$ & $\mathbf{2 0 3 0}$ \\
\hline Demand reduction from Current Policies & -0.24 & -0.43 & -0.64 \\
\hline Demand reduction from New Policies & -0.02 & -0.20 & -0.45 \\
\hline
\end{tabular}

Table 1: EU demand reduction in the Unilateral European Climate Policy scenario compared to the reference scenarios in percentage (source: own after IEA, 2010)

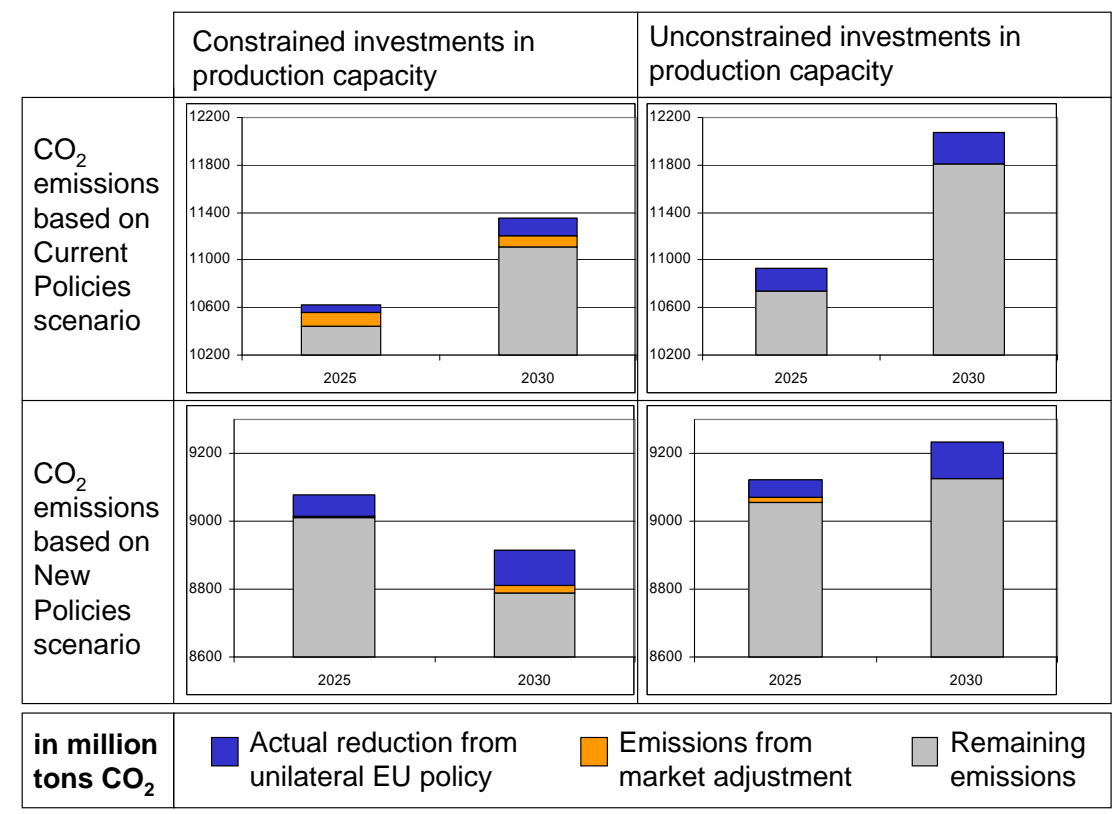

Figure 5: Worldwide emissions reductions and adverse market adjustments in the Unilateral European Climate Policy model scenario (source: own modeling results)

mate effort. This is especially the case in the Current Policies framework with a constrained market condition. In that case global coal demand is high and the market somewhat constrained so that a reduction in European coal demand allows the Asian countries to consume significantly more. In 2025, the market adjustment nullifies $66 \%$ of the European reduction target and $29 \%$ in 2030 . In the unconstrained case the market adjustment is negligible but global emissions are much higher.

In the New Policies framework the market adjustment is much lower. It is interesting to note that the market condition has a high impact on the global level of emissions and on the market adjustment mechanism. In 2030, in the constrained case the mechanism works as described above for the Current Policies constrained case: the European reduction allows Asia to consume more through the global price mechanism. However in the unconstrained case, in 2025, the market adjustment with considerably lower prices occurs because more quantities are potentially available when there is no constraint. The lower European consumption has a significant 
impact on prices that it has not in the constrained case where global demand remains slightly restricted.

We can conclude that market adjustments are very likely to occur but that their adverse effect is generally low and will not overcompensate the emissions reductions from Europe. This is due to the relatively small size of EU demand in the global steam coal demand. However, in the case of a low level of global climate policy as in the Current Policies scenario the adverse market adjustment effect can be very high. Thus; it is logical for the European Commission to say that it will aim at a $30 \%$ emissions reduction goal only if other countries take a binding commitment to higher reduction goals. In such a case, that can be described by the New Policies scenario, Europe can always go an extra mile without expecting too much adverse market adjustments.

\subsection{Yasuní-type supply-side policy in Indonesia}

The Yasuní-ITT initiative proposed by the Ecuadorian government aims at combating global warming, protecting biodiversity and indigenous people as well as implementing a sustainable social and energetic development by refraining indefinitely from exploiting the oil reserves of the Ishpingo-Tambococha-Tiputini (ITT) oil field within the Yasuní National Park (Larrea, 2010). ${ }^{4}$ This field represents $20 \%$ of the Ecuadorian oil reserves and the initiative requires a capital contribution of at least half of the earnings Ecuador would receive from exploitation. Valuated at 76.38 USD per barrel this represents a sum of 3.635 billion USD supplied by the international community to a fund managed by the United Nations Development Programme. The initiative represents $407 \mathrm{Mt} \mathrm{CO}_{2}$ saved from not using the oil resource and an additional $820 \mathrm{Mt} \mathrm{CO}_{2}$ mitigation potential over 20 years from avoided deforestation and forest management (Larrea, 2010).

For the Indonesian scenario, we use the same idea and apply it to another geographic area and to our fuel of interest in this paper, steam coal. The bulk of coal exploitation in Indonesia takes place on the island of Kalimantan (formerly known as Borneo). This island is home to one of the greatest rainforests in the world and a treasure of biodiversity that is endangered by coal mining through deforestation and local air and water pollution. Fatah (2008) points out that coal mining has little to no beneficial effects on the local economy. The revenues and benefits go to private companies and the government. Thus, one could imagine a supply-side climate policy mechanism similar to the Yasuní-ITT Initiative to preserve the Indonesian forest and prevent the extraction, export and carbon dioxide emissions from coal

\footnotetext{
${ }^{4}$ http://yasuni-itt.gob.ec/
} 


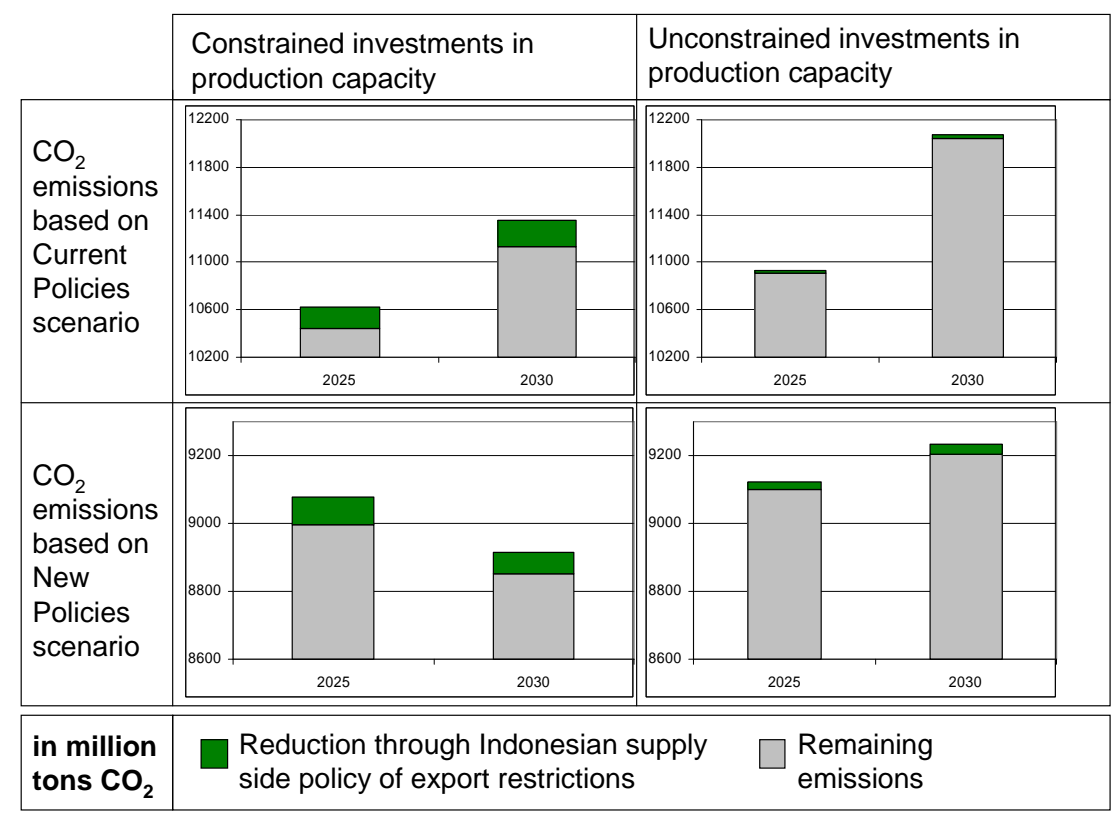

Figure 6: Worldwide emissions reduction in the Indonesian supply-side policy scenario. (source: own modeling results)

albeit still allowing a local use of steam coal for power generation. In our particular case we modeled this policy as an export restriction (maximum quantity that can be exported in a given year) for Indonesia as follows: 2006 to 2015, no restriction; 2020: 50 Mtpa; 2025: 25 Mtpa; 2030: 0 Mtpa (phase-out of export).

In our reference cases for all policy environments Indonesia is the most important supplier to the global market with yearly export values that can be higher than $200 \mathrm{Mt}$. The results of the Indonesia scenario run with export restrictions are summarized in Figure 6. We see that the reduction effect is the strongest in the case of a constrained global market because it is hard to find alternative suppliers on the world market that could replace the lacking Indonesian exports. In the unconstrained case the effect is lower as Indonesian coal is substituted by other producers. Also we must be wary that such an effect may limited in time as the supply gap may be covered by other producers over time.

\subsection{CCS fast roll-out}

Carbon capture and storage (CCS) is a set of technologies that aim at a reduction of carbon dioxide emissions into the atmosphere by separating and capturing the $\mathrm{CO}_{2}$ at the power plant and transporting it to a geological sink where it will be compressed and stored underground (see IPCC, 2005). The CCS technology is regarded by the 
IPCC and by the IEA to be one of the major options for climate change mitigation. However, as of 2011 there are only about 10 pilot CCS plants operating in the world and not a single large scale operation (22 are planned to start operating between 2014 and 2020). ${ }^{5}$ In the IEA (2010) WEO scenarios, CCS plays a significant role in the 450 ppm scenario after 2025 and a smaller role in the New Policies scenario but only after 2030. There are various technological and political barriers to the implementation that explain this late roll-out of the CCS technology (see Gibbins and Chalmers, 2008).

In our CCS fast roll-out scenario we assume that technological breakthroughs, a favorable regulatory framework as well as a strong political support create the conditions for a fast CCS roll-out with significant capacities coming in as early as 2020. Such a scenario makes only sense in an overall environment of ambitious climate policy, thus we apply this additional policy shock in the New Policies and the $450 \mathrm{ppm}$ policy framework only, as shown in Figure 3. For this scenario we assume that the worldwide installed capacities of coal power plants with CCS projected by the IEA (2010) WEO in the 450 ppm scenario are put in place five years earlier. We assume that half of this additional capacity replaces existing older coal power plants, the other half is integrated in the power system as additional capacity, successfully competing with other technologies. Furthermore for our coal demand calculations, we assume that CCS power plants have a $38 \%$ efficiency and a capacity factor of $82 \%$. Thus, we actually compute two additional demand shocks: one coming from half of the CCS capacity that is added to the coal demand and the other because the lower efficiency of CCS power plants requires additional coal to produce the same amount of energy. The assumed capacities of CCS for our modeling runs are shown in Table 2 divided into the following regions: OECD + , Other Major Economies and Other Countries. ${ }^{6}$

\begin{tabular}{|l|c|c|c|}
\hline & $\mathbf{2 0 2 0}$ & $\mathbf{2 0 2 5}$ & $\mathbf{2 0 3 0}$ \\
\hline World & 150 & 286 & 423 \\
\hline OECD+ (incl. Europe, USA, Japan) & 72 & 134 & 197 \\
\hline OME (incl. China, Russia, South Africa) & 74 & 145 & 216 \\
\hline OC (incl. India, South-East Asia) & 4 & 6 & 9 \\
\hline
\end{tabular}

Table 2: Assumed installed capacities of coal power plants with CCS for the CCS scenario in GW (source: own calculations based on IEA, 2010)

The results of the CCS scenario are presented in Figure 7. Let us start analyzing the scenario based on the New Policies climate policy framework. CCS is

\footnotetext{
${ }^{5}$ source: Carbon Capture and Sequestration Technologies Program at MIT (http://sequestration.mit.edu/tools/projects/index.html).

${ }^{6}$ See IEA (2010) for an exact definition of these aggregates.
} 


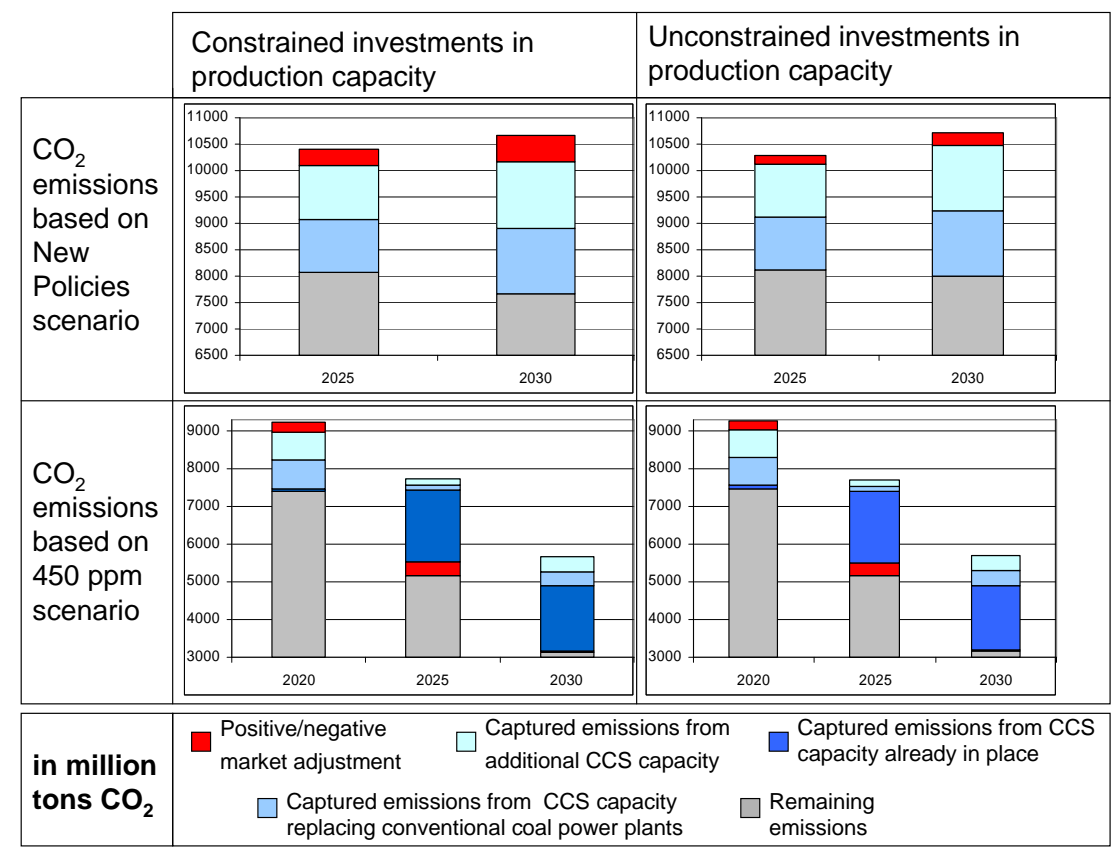

Figure 7: Worldwide emissions in the CCS scenario (source: own modeling results)

insignificant in the reference scenario and therefore the additional CCS capacity, half of which leads to new coal demand, has a strong effect on the market. We see a market adjustment that is positive for the climate. The higher demand leads to higher prices that lead to a reduction of demand from conventional power plants. This effect is very strong in a constrained market environment and significant in the unconstrained environment.

In the scenario based on the $450 \mathrm{ppm}$ climate policy environment the global coal demand is so low that the market condition has very little effect on the scenario outcomes. However, we observe different market adjustment effects. In 2020, there is very little CCS in the reference case so that the additional demand for coal creates a market adjustment effect with high prices similar to the one described in the New Policies case. In 2025, we have an opposite "negative" market adjustment effect with more emissions. This is due to an effect of decreasing demand with a capacity effect: in 2020 capacities are build up to serve the additional demand and they create a slight oversupply situation in 2025. This effect overcompensates the little CCS addition but is only temporary.

In the case of a relatively intense global level of climate policy, such as in the New Policies framework, a faster implementation of CCS would be very beneficial. We expect that, additionally to the captured quantities of $\mathrm{CO}_{2}$, a positive market adjustment will further reduce coal consumption and emissions. The picture is less 
clear in the $450 \mathrm{ppm}$ case. But in the case this very ambitious climate scenario becomes reality in the future, some amount of market adjustment on the steam coal market has little relevance in the overall required transformation of the global energy system anyways.

\section{Conclusions and policy recommendations}

Using the COALMOD-World model we are able to make differentiated conclusions about the efficiency of different types of climate policy alternatives through their interplay with the global coal market in various market conditions.

If we take a European and policy-oriented view of this results, several conclusions and recommendations can be drawn to prioritize different climate policy options. In the case of a European unilateral climate policy in a context of little global climate effort, we can expect adverse market adjustment effects that can compensate up to $2 / 3$ of European emissions reductions. Thus the first priority of the European climate policy should be to reach a global level of climate policy that is at least at the level of the non-binding agreements taken in recent climate conferences in Copenhagen in 2009 and in

in 2010. A global climate policy has the biggest effect on global carbon emissions coming from the coal sector. If this is reached the EU can always go further in reducing its steam coal consumption without risking too much adverse effects from the global market.

A supply-side climate policy in Indonesia also has some significant $\mathrm{CO}_{2}$ emissions reduction effects that are potentially in the same order of magnitude as the European unilateral climate policy. It is interesting to note that this supply-side policy has its best performance in the context where the European unilateral climate policy sees the most important negative market adjustment effects, i.e. when there is a low intensity of global climate policy and when the market is constrained. Thus the EU could try and pursue such an unconventional climate policy as a way to hedge against adverse effects from its own domestic climate policy. Such a policy in Indonesia would also have additional beneficial effects for nature conservation, the protection of biodiversity as well as avoided $\mathrm{CO}_{2}$ emission from deforestation.

The first advantage of a policy that aims at a faster roll-out of the CCS technology is the emissions reduction through the capture of $\mathrm{CO}_{2}$. Climate beneficial market adjustment effects can also occur. A significant impact of CCS can only be expected if this technology is implemented globally. Thus the strategy of the EU should be to support the roll-out of this technology in Europe but also abroad through international cooperation. 
If we rank all the different policy options examined in this paper using the COALMOD-World model with regard to their effectiveness in reducing carbon emissions from steam coal use on a global level, we obtain the following order of priority for EU climate policy. First, the EU should aim at establishing a strong globally binding climate agreement. Secondly, the EU should support a fast roll-out of CCS, both in the EU and globally. Thirdly, on the same level, the EU can set a more stringent emissions reduction goal for itself and be open to more unconventional climate policies such as the described supply-side reduction in Indonesia through production and export limitations. 


\section{References}

Böhringer, C. 1998. "The Synthesis of Bottom-up and Top-down in Energy Policy Modeling." Energy Economics 20(3):233 - 248.

Böhringer, C., C. Fischer and K.E. Rosendahl. 2010. "The Global Effects of Subglobal Climate Policies." The BE Journal of Economic Analysis and Policy 10(2).

Böhringer, C. and T.F. Rutherford. 2000. "Decomposing the Cost of Kyoto: a Global CGE Analysis of Multilateral Policy Impacts." ZEW Discussion Papers 00-11.

Bovenberg, A.L. and L.H. Goulder. 2005. "Efficiency Costs of Meeting IndustryDistributional Constraints under Environmental Permits and Taxes." The RAND Journal of Economics 36(4):951 - 971.

Demailly, D. and P. Quirion. 2008. "European Emission Trading Scheme and Competitiveness: A Case Study on the Iron and Steel Industry." Energy Economics 30(4):2009 - 2027.

Dröge, Susanne. 2009. "Tackling Leakage in a World of Unequal Carbon Prices, Synthesis Report." Technical report, Climate Strategies.

Fatah, Luthfi. 2008. "The Impacts of Coal Mining on the Economy and Environment of South Kalimantan Province, Indonesia." ASEAN Economic Bulletin 25(1).

Gibbins, Jon and Hannah Chalmers. 2008. "Carbon Capture and Storage." Energy Policy 36(12):4317 - 4322.

Haftendorn, Clemens and Franziska Holz. 2010. "Modeling and Analysis of the International Steam Coal Trade." The Energy Journal 31(4):201-225.

Haftendorn, Clemens, Franziska Holz and Christian von Hirschhausen. 2010. "COALMOD-World: A Model to Assess International Coal Markets until 2030." DIW Discussion Paper 1067. Berlin.

Holz, Franziska, Christian von Hirschhausen and Claudia Kemfert. 2008. "A Strategic Model of European Gas Supply (GASMOD)." Energy Economics 30(3):766788.

Hotelling, Harold. 1931. "The Economics of Exhaustible Resources." Journal of Political Economy 39(2):137-175.

\begin{tabular}{|c|c|c|c|c|c|c|}
\hline Hubbert, & M. & King. & 1959. & "Techniques & of & Prediction \\
\hline with & Application & to & the & Petroleum & Industry." & URL \\
\hline
\end{tabular}


Huppmann, Daniel, Ruud Egging, Franziska Holz, Christian von Hirschhausen and Sophia Ruster. 2011. "The World Gas market in 2030 - Development Scenarios using the World Gas Model." International Journal of Global Energy Issues 35(1):64 -84 .

IEA. 2010. World Energy Outlook 2010. Paris: OECD.

IPCC. 2005. "IPCC Special Report on Carbon Dioxide Capture and Storage." URL http://www.ipcc.ch/pdf/special-reports/srccs/srccs_wholereport.pdf.

IPCC. 2011. "The IPCC Special Report on Renewable Energy Sources and Climate Change Mitigation - SRREN Generic Presentation." URL http://srren.ipcc-wg3.de/ipcc-generic-presentation.

Kemfert, Claudia. 2002. "Global Economic Implications of Alternative Climate Policy Strategies." Environmental Science $\&$ Policy 5(5):367 - 384.

Larrea, Carlos. 2010. "Yasuni-ITT: An Initiative to Change History." URL http://yasuni-itt.gob.ec/wp-content/uploads/initiative_ change_history_sep.pdf, Government of Ecuador.

Lise, Wietze and Benjamin F. Hobbs. 2008. "Future Evolution of the Liberalised European Gas Market: Simulation Results with a Dynamic Model." Energy 33(7):989-1004.

Lise, Wietze, Benjamin F. Hobbs and Frits van Oostvoorn. 2008. "Natural Gas Corridors Between the EU and its Main Suppliers: Simulation Results with the Dynamic GASTALE model." Energy Policy 36(6):1890 - 1906, URL http://www.sciencedirect.com/science/article/pii/S030142150800058X.

Lynch, Michael C. 2003. "The New Pessimism about Petroleum Resources: Debunking the Hubbert Model (and Hubbert Modelers)." Minerals and Energy 18(1):2132.

Patzek, Tadeusz W. and Gregory D. Croft. 2010. "A Global Coal Production Forecast with Multi-Hubbert Cycle Analysis." Energy 35(8):3109-3122.

Paulus, Moritz and Johannes Trüby. 2011a. "Coal Lumps vs. Electrons: How do Chinese Bulk Energy Transport Decisions Affect the Global Steam Coal Market?" Energy Economics In Press, Corrected Proof.

Paulus, Moritz and Johannes Trüby. 2011b. "Market Structure Scenarios in International Steam Coal Trade." EWI Working Paper 2011/02. 
Perman, Roger, Yue Ma, James McGilvray and Michael Common. 1999. Natural Resource and Environmental Economics. Harlow, England: Pearson/ Addison Wesley, 2nd edition.

Pindyck, Robert S. 1981. "Models of Resource Markets and the Explanation of Resource Price Behaviour." Energy Economics 3(3):130 - 139.

Sinn, Hans-Werner. 2008. "Public Policies Against Global Warming: a Supply Side Approach." International Tax and Public Finance 15(4):360-394, URL http://ideas.repec.org/a/kap/itaxpf/v15y2008i4p360-394 .html. 


\section{Appendix}

\begin{tabular}{|l|c|c|c|c|c|c|}
\hline Demand node & 2006 & 2010 & 2015 & 2020 & 2025 & 2030 \\
\hline C_NFB & -0.3 & -0.3 & -0.3 & -0.4 & -0.4 & -0.4 \\
\hline C_ITA & -0.3 & -0.3 & -0.3 & -0.4 & -0.4 & -0.4 \\
\hline C_RUS_Siberia & -0.3 & -0.3 & -0.3 & -0.4 & -0.4 & -0.4 \\
\hline C_RUS_Central & -0.3 & -0.3 & -0.3 & -0.4 & -0.4 & -0.4 \\
\hline C_CAN & -0.3 & -0.3 & -0.3 & -0.4 & -0.4 & -0.4 \\
\hline C_THA & -0.3 & -0.3 & -0.3 & -0.4 & -0.4 & -0.4 \\
\hline C_VNM & -0.3 & -0.3 & -0.3 & -0.4 & -0.4 & -0.4 \\
\hline C_ESP & -0.3 & -0.3 & -0.3 & -0.4 & -0.4 & -0.4 \\
\hline C_FIN & -0.3 & -0.3 & -0.3 & -0.4 & -0.4 & -0.4 \\
\hline C_JPN & -0.3 & -0.3 & -0.3 & -0.4 & -0.4 & -0.4 \\
\hline C_TUR & -0.3 & -0.3 & -0.3 & -0.4 & -0.4 & -0.4 \\
\hline C_DEU & -0.3 & -0.3 & -0.3 & -0.4 & -0.4 & -0.4 \\
\hline C_PRT & -0.2 & -0.2 & -0.2 & -0.3 & -0.3 & -0.4 \\
\hline C_PHL & -0.2 & -0.2 & -0.2 & -0.3 & -0.3 & -0.4 \\
\hline C_MYS & -0.2 & -0.2 & -0.2 & -0.3 & -0.3 & -0.4 \\
\hline C_MNG & -0.2 & -0.2 & -0.2 & -0.3 & -0.3 & -0.4 \\
\hline C_UKR & -0.2 & -0.2 & -0.2 & -0.3 & -0.3 & -0.4 \\
\hline C_GBR & -0.2 & -0.2 & -0.2 & -0.3 & -0.3 & -0.4 \\
\hline C_KOR & -0.2 & -0.2 & -0.2 & -0.3 & -0.3 & -0.4 \\
\hline C_IDN & -0.2 & -0.2 & -0.2 & -0.3 & -0.3 & -0.4 \\
\hline C_USA_Rocky & -0.2 & -0.2 & -0.2 & -0.3 & -0.3 & -0.4 \\
\hline C_USA_Central & -0.2 & -0.2 & -0.2 & -0.3 & -0.3 & -0.4 \\
\hline C_USA_South & -0.2 & -0.2 & -0.2 & -0.3 & -0.3 & -0.4 \\
\hline C_USA_Gulf & -0.2 & -0.2 & -0.2 & -0.3 & -0.3 & -0.4 \\
\hline C_USA_East & -0.2 & -0.2 & -0.2 & -0.3 & -0.3 & -0.4 \\
\hline C_DNK & -0.1 & -0.1 & -0.1 & -0.2 & -0.3 & -0.4 \\
\hline C_TWN & -0.1 & -0.1 & -0.1 & -0.2 & -0.3 & -0.4 \\
\hline C_MAR & -0.1 & -0.1 & -0.1 & -0.2 & -0.3 & -0.4 \\
\hline C_IND_East & -0.1 & -0.1 & -0.1 & -0.2 & -0.3 & -0.4 \\
\hline C_IND_North & -0.1 & -0.1 & -0.1 & -0.2 & -0.3 & -0.4 \\
\hline C_IND_West & -0.1 & -0.1 & -0.1 & -0.2 & -0.3 & -0.4 \\
\hline C_IND_South & -0.1 & -0.1 & -0.1 & -0.2 & -0.3 & -0.4 \\
\hline C_ISR & -0.1 & -0.1 & -0.1 & -0.2 & -0.3 & -0.4 \\
\hline C_KAZ & -0.1 & -0.1 & -0.1 & -0.2 & -0.3 & -0.4 \\
\hline C_CHN_Northeast & -0.1 & -0.1 & -0.1 & -0.2 & -0.3 & -0.4 \\
\hline C_CHN_SIS & -0.1 & -0.1 & -0.1 & -0.2 & -0.3 & -0.4 \\
\hline C_CHN_Main & -0.1 & -0.1 & -0.1 & -0.2 & -0.3 & -0.4 \\
\hline C_CHN_Eastern & -0.1 & -0.1 & -0.1 & -0.2 & -0.3 & -0.4 \\
\hline C_CHN_South & -0.1 & -0.1 & -0.1 & -0.2 & -0.3 & -0.4 \\
\hline C_POL & -0.1 & -0.1 & -0.1 & -0.2 & -0.3 & -0.4 \\
\hline C_ZAF & -0.1 & -0.1 & -0.1 & -0.2 & -0.3 & -0.4 \\
\hline
\end{tabular}

Table 3: Demand elasticities 